\title{
Northern blotting analysis of microRNAs, their precursors and RNA interference triggers
}

\author{
Edyta Koscianska, Julia Starega-Roslan, Lukasz J Sznajder, Marta Olejniczak, Paulina Galka-Marciniak and \\ Wlodzimierz J Krzyzosiak
}

\begin{abstract}
Background: Numerous microRNAs (miRNAs) have heterogeneous ends resulting from imprecise cleavages by processing nucleases and from various non-templated nucleotide additions. The scale of miRNA end-heterogeneity is best shown by deep sequencing data revealing not only the major miRNA variants but also those that occur in only minute amounts and are unlikely to be of functional importance. All RNA interference (RNAi) technology reagents that are expressed and processed in cells are also exposed to the same machinery generating endheterogeneity of the released short interfering RNAs (siRNAs) or miRNA mimetics.

Results: In this study we have analyzed endogenous and exogenous RNAs in the range of 20-70 nt by highresolution northern blotting. We have validated the results obtained with northern blotting by comparing them with data derived from miRNA deep sequencing; therefore we have demonstrated the usefulness of the northern blotting technique in the investigation of miRNA biogenesis, as well as in the characterization of RNAi technology reagents.

Conclusions: The conventional northern blotting enhanced to high resolution may be a useful adjunct to other miRNA discovery, detection and characterization methods. It provides quantitative data on distribution of major length variants of abundant endogenous miRNAs, as well as on length heterogeneity of RNAi technology reagents expressed in cells.
\end{abstract}

\section{Background}

MicroRNAs (miRNAs) are endogenous short RNAs $(\sim 22 \mathrm{nt})$ that control gene expression at the posttranscriptional level. There is growing evidence that miRNAs regulate various physiological processes and are frequently misregulated in many diseases [1-9]. The biogenesis of animal miRNAs includes two RNA cleavage steps (reviewed in [10-13]). First, in the nucleus, primary miRNA transcripts (pri-miRNA) are cleaved into approximately 60 nucleotide-long pre-miRNA precursors by the ribonuclease Drosha acting together with DGCR8 protein within the complex named Microprocessor $[14,15]$. Then, the pre-miRNAs are exported to the cytoplasm by Exportin-5 [16,17] and cleaved further by the ribonuclease Dicer protein complex into $\sim 20$ nucleotide-long miRNA duplexes $[18,19]$. One of the two RNA strands becomes functional miRNA via

\footnotetext{
*Correspondence: wlodkrzy@ibch.poznan.pl

Laboratory of Cancer Genetics, Institute of Bioorganic Chemistry, Polish Academy of Sciences, Noskowskiego 12/14 Str., 61-704 Poznan, Poland
}

Argonaute protein binding, and the other is released and degraded [20,21]. Mature miRNAs are heterogeneous in length, varying between 19 and 25 nt [22-25]. The primary source of miRNA length heterogeneity is imprecise cleavage by the ribonucleases Drosha and Dicer [26]. Further, miRNA 5'-end selection occurs upon Argonaute protein binding [27]. The miRNAs that differ in their 5 '-ends have different seed sequences and may regulate different sets of targets [24,28-30]. Detection of the cellular levels of individual length variants of miRNAs with high precision is therefore very important. Similarly, determination of the exact length distribution of reagents released from the vectors used in RNAi and miRNA technologies is of importance because it may influence their performance in cells [31]. It is also advantageous to monitor the lengths of reagents released from the vectors with regard to the off-target effects that these products may cause $[32,33]$.

Numerous reports have described various improvements of the northern blotting technique [34-39]. In 
this study, we use the method refined for extremely high-resolution detection of miRNAs, pre-miRNAs, siRNAs released from vectors, and any short RNAs of corresponding lengths. We demonstrate the usefulness of this northern blotting procedure by showing examples of its application in miRNA and RNAi fields to evaluate the precision of Drosha and Dicer cleavages.

\section{Results and discussion}

We show here that northern blotting of short RNAs that are 20-70 nt in length may provide insightful information on the distribution of individual length variants of siRNAs, miRNAs and their precursors in cells. We first show that high-resolution northern blotting and deep sequencing give similar results for abundant miRNAs. Then, we advance our recent observations showing utility of this northern blotting protocol for evaluating precision of Drosha and Dicer cleavages during human miRNA biogenesis [26]. Finally, we put special emphasis on the need for better characterization of reagents released from expression constructs used to activate RNAi in cells.

\section{Correlation between high-resolution northern blotting and deep sequencing results}

An increasingly popular high-throughput technology for miRNA discovery and expression profiling is deep sequencing [22-25]. To validate high-resolution northern blotting as a suitable method for miRNA length heterogeneity studies, we compared the results obtained using this method with the deep sequencing results obtained by others using Illumina sequencing-by-synthesis platform for miRNA discovery in mice [24]. The following endogenous mouse miRNAs that differ in length heterogeneity have been analyzed: miR-9, miR-9*, miR-29, miR-124, miR-132 and miR-137 specific for neuronal tissues, as well as miR-1 and miR-206 specific for muscle tissues (Figure 1). Total RNAs were extracted from selected brain sections (cortex, cerebellum, striatum and thalamus) or muscle tissues (heart and skeletal muscles from legs), and the miRNAs abundantly expressed in these tissues were detected by northern blotting with specific probes. To evaluate relative levels of miRNA heterogeneity, radioactive northern blotting signals were quantified by phosphorimaging and the percentages of individual length variants in the miRNA fractions were calculated. Similarly, the distribution of miRNA length variants was calculated from deep sequencing data [24] (Additional file 1: Supplemental Table S1). These two datasets correlated well with each other (Figure 1). However, it should be borne in mind that the degree of correlation may vary when a different sequencing platform and/or data filtering system is used. Of all the analyzed miRNAs, length heterogeneity was greatest for
miR-124, which is in accordance with deep sequencing results showing that some miRNAs have multiple isoforms $[22,24,25]$. In contrast to deep sequencing, northern blotting shows only the most abundant miRNA variants. This feature may be considered advantageous because only highly expressed miRNA variants are of functional importance [24].

\section{Application of northern blotting in studies of miRNA and pre-miRNA length heterogeneity}

Northern blotting analysis with single-nucleotide resolution makes it possible to detect both miRNA and premiRNA length variants. We have therefore found this method useful in our studies of molecular sources of miRNA length heterogeneity [26]. Such heterogeneity has already been observed by deep sequencing in the case of miRNAs [23,29] and by cloning in the case of pre-miRNAs [40]. The pre-miRNA heterogeneity has its primary source in the imprecise pri-miRNA cleavage by Drosha $[41,42]$. The miRNA heterogeneity results from imprecise cleavages by both Drosha and Dicer and can be further biased at the AGO2 programming step [27] and by various post-cleavage modifications, such as an untemplated nucleotide addition [22,43]. Here, we show examples of northern blots of endogenous mouse miRNAs (Figure 1A), as well as of miRNAs and pre-miRNAs overexpressed from vector constructs (Figure 2). We used the miRNA overexpression system because only a limited number of known miRNAs are expressed in a given cell line or tissue, and only a fraction of these miRNAs are expressed at levels detectable by northern blotting. Hence, the use of a miRNA overexpression system may assist miRNA biogenesis studies by increasing cellular levels of miRNAs and, more importantly, facilitating the detection of miRNA precursors. The miRNAs and pre-miRNAs, shown here as examples, reveal different levels of length heterogeneity. Specifically, three length variants were observed for miR-191 and miR-496, whereas only one was seen for miR-93 (Figure 2A). Similarly, individual pre-miRNAs differed in the number of length variants (Figure 2B). The level of length heterogeneity observed here is in agreement with the results of our large-scale analysis of Drosha and Dicer cleavage specificities [26]. The length heterogeneity detected by northern blotting can be quantitatively evaluated by analyzing appropriate signal intensities (Figure 2, right panels), making high-resolution northern blotting an even more reliable method.

\section{High-resolution northern blotting in siRNA studies}

Short hairpin RNAs (shRNAs) may be constructed in two ways; they may have antisense (guide) strands in the 3' or 5 ' arm of the shRNA stem (discussed in [44]). We designed both sense-antisense (R-type) and antisense-sense (L-type) 


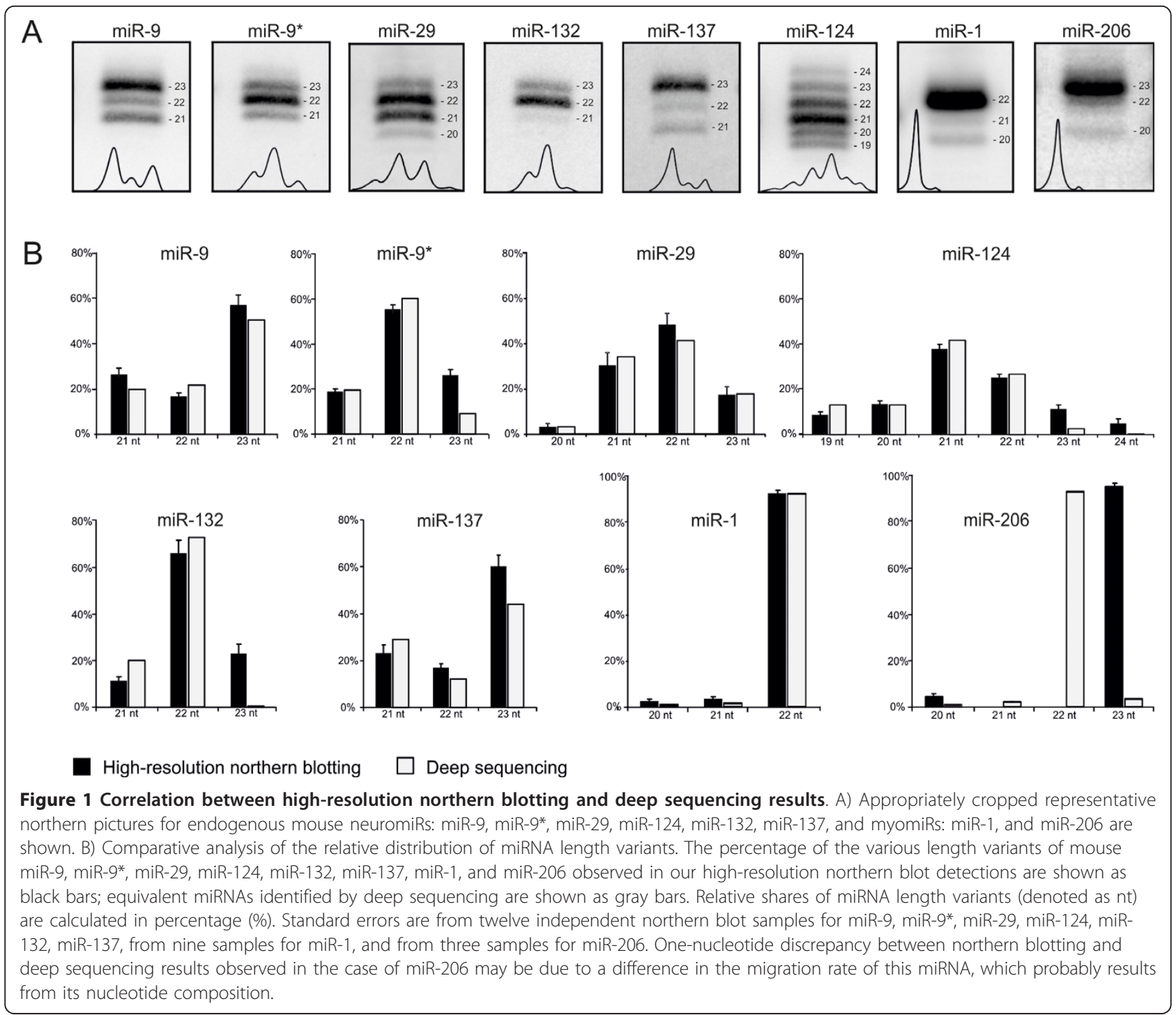

shRNAs having the same guide sequence specific for spinocerebellar ataxia type 3 (ATXN3) mRNA (for simplicity, these shRNAs are hereinafter referred to as R-shSCA3 and L-shSCA3) and cloned them into a pSilencer vector (Ambion). To estimate the length of siRNAs excised from the shRNAs by Dicer, we transfected HEK 293T cells with the vector constructs and performed high-resolution northern blotting analysis. Probes detecting either the sense or antisense strand of R-shSCA3 and L-shSCA3 were used for northern blotting (Figure 3A). The siRNAs generated from both types of shRNAs were heterogeneous in length, and their length variants were easily distinguishable at 1-nt resolution. The hybridization signals obtained by detection with appropriate probes were unequal in intensity, but the distribution of particular length variants was only slightly different, regardless of the location of the
shRNA guide strand. It should be borne in mind that the observed siRNA length heterogeneity may result not only from imprecise Dicer cleavage of the shRNA but also from heterogeneity at its 3'end to which the PAZ domain of Dicer anchors. Therefore, the monitoring of RNA reagents released from shRNAs is important. The shRNAs encoded by appropriate vectors are transcribed from U6 or H1 RNA polymerase III (Pol III) promoters [45]. The start of transcription is strictly defined as the +1 position of the promoter in the vector, but termination is less accurate and occurs within a short stretch of several uracil residues in the transcript [46]. Hence, the length heterogeneity of shRNAs may be solely the result of the different lengths of the oligo-U tails at the 3' end. Using high-resolution northern blotting, we analyzed shRNAs and their siRNA products generated from vectors with transcription 


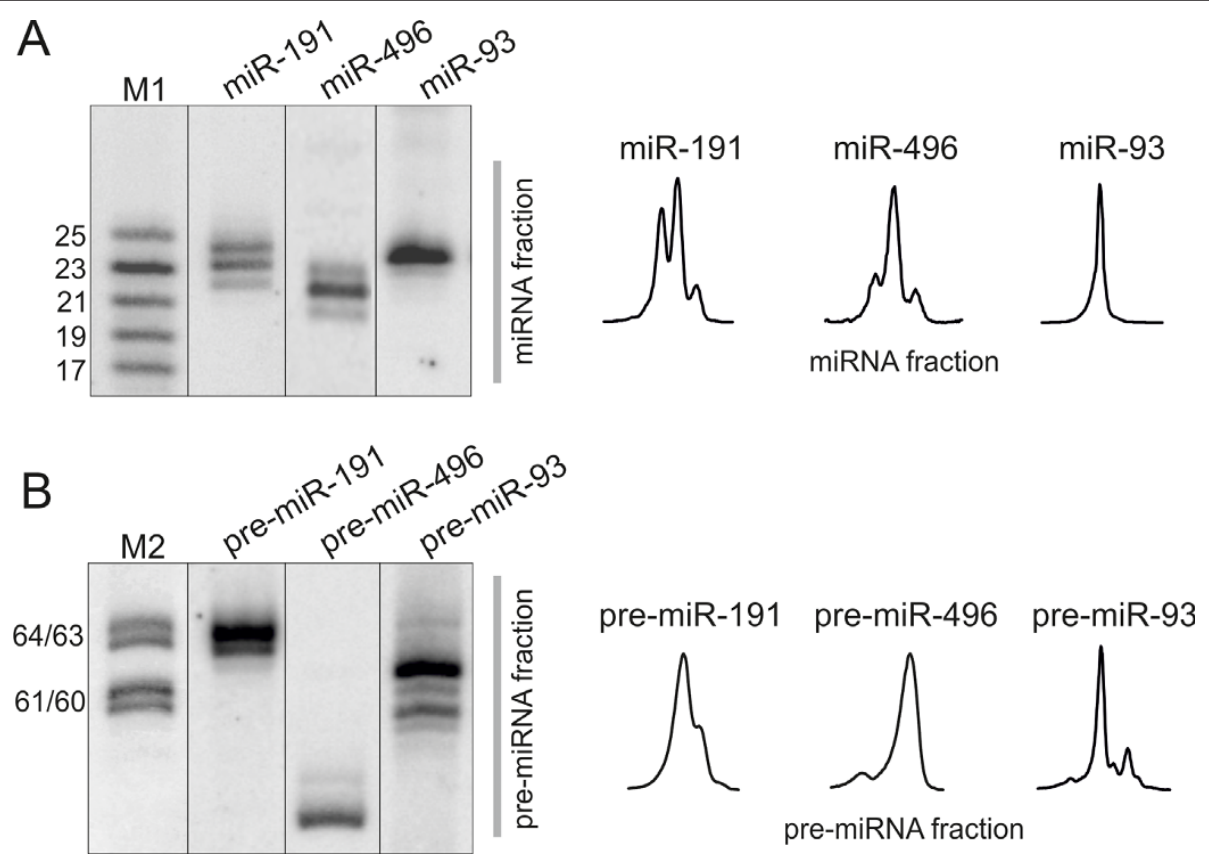

Figure 2 Detection of heterogeneous miRNAs and pre-miRNAs. Examples of heterogeneous miRNAs and pre-miRNAs overexpressed in HEK 293 T cells and detected with single-nucleotide resolution, as shown in the figure. A) miRNAs: miR-191, miR-496, miR-93 resolved in the range of $\sim 17-25$ nt. B) pre-miRNAs: pre-miR-191, pre-miR-496, and pre-miR-93 resolved in the range of $\sim 60-70$ nt. M-lanes denote the appropriate radiolabeled RNA oligonucleotide markers (ORNs); M1 denotes 17, 19, 21, 23, 25-nt ORNs for miRNA detection (A) and M2 denotes 60/61 and 63/ 64-nt ORNs for pre-miRNA detection (B). Quantitative representations of miRNA and pre-miRNA variants obtained from phosphorimaging analyses are shown schematically.

termination signals composed of different numbers of thymidines (4T and 6T). We transfected HEK 293T cells with vectors carrying either single stranded RNA composed of nine CUG repeats (ssRNA CUG9) or double stranded RNA forming a hairpin, composed of seven CAG/CUG repeats (shRNA CAG/CUG7). These constructs were driven by the $\mathrm{H} 1$ promoter but with either $4 \mathrm{~T}$ or $6 \mathrm{~T}$ stretches as the termination signal (Figure 3B). As we expected, the ssRNA CUG9 transcript not forming a hairpin with a distinctive loop was not processed by Dicer, and we observed heterogeneous products with a length range of $\sim 30-35 \mathrm{nt}$ that were derived solely from unspecific transcription termination. We also observed length heterogeneity in siRNA products released from both shRNA constructs. Moreover, the pattern of length distribution varied. In the case of the shCAG/CUG terminating at 4T, the longer siRNA variants ( 23-24 nt) dominated in the siRNA pool, whereas in the case of the same shRNA terminating at $6 \mathrm{~T}$, shorter siRNA variants ( 22-23 nt) were more abundant. These examples show that several obstacles to achieving effective shRNA design still need to be overcome $[47,48]$, and high-resolution northern blotting may be helpful in addressing these issues. The imprecise processing of shRNAs in cells has important implications for siRNA technology because it results in the production of only a fraction of silencing reagent with the desired sequence. This issue is especially important for allele-specific applications of RNAi technology in which a transcript is targeted at a single-nucleotide polymorphism (SNP) linked to a mutation.

\section{Conclusions}

In this study we have shown that the optimized highresolution northern blotting can be used to analyze endogenous and exogenous RNAs in the range of 20-70 nt. We demonstrated the usefulness of this technique in the investigation of miRNA biogenesis as well as in the characterization of RNAi technology reagents. We have validated the high-resolution northern blotting as a reliable tool for length heterogeneity analysis of miRNAs and their precursors and have presented examples of its application in miRNA and siRNA studies. The method can be used in a variety of applications to verify mechanisms of RNAi-mediated effects. However, we understand that there is a limit to the interpretation of northern blots, and other techniques have to be used to provide complementing information. The techniques allowing precise mapping of both 5' and 3' ends of processed products include deep sequencing, primer extension (5') and rapid amplification of cDNA ends (5' and 3' RACE). These methods, when used jointly, will provide more 

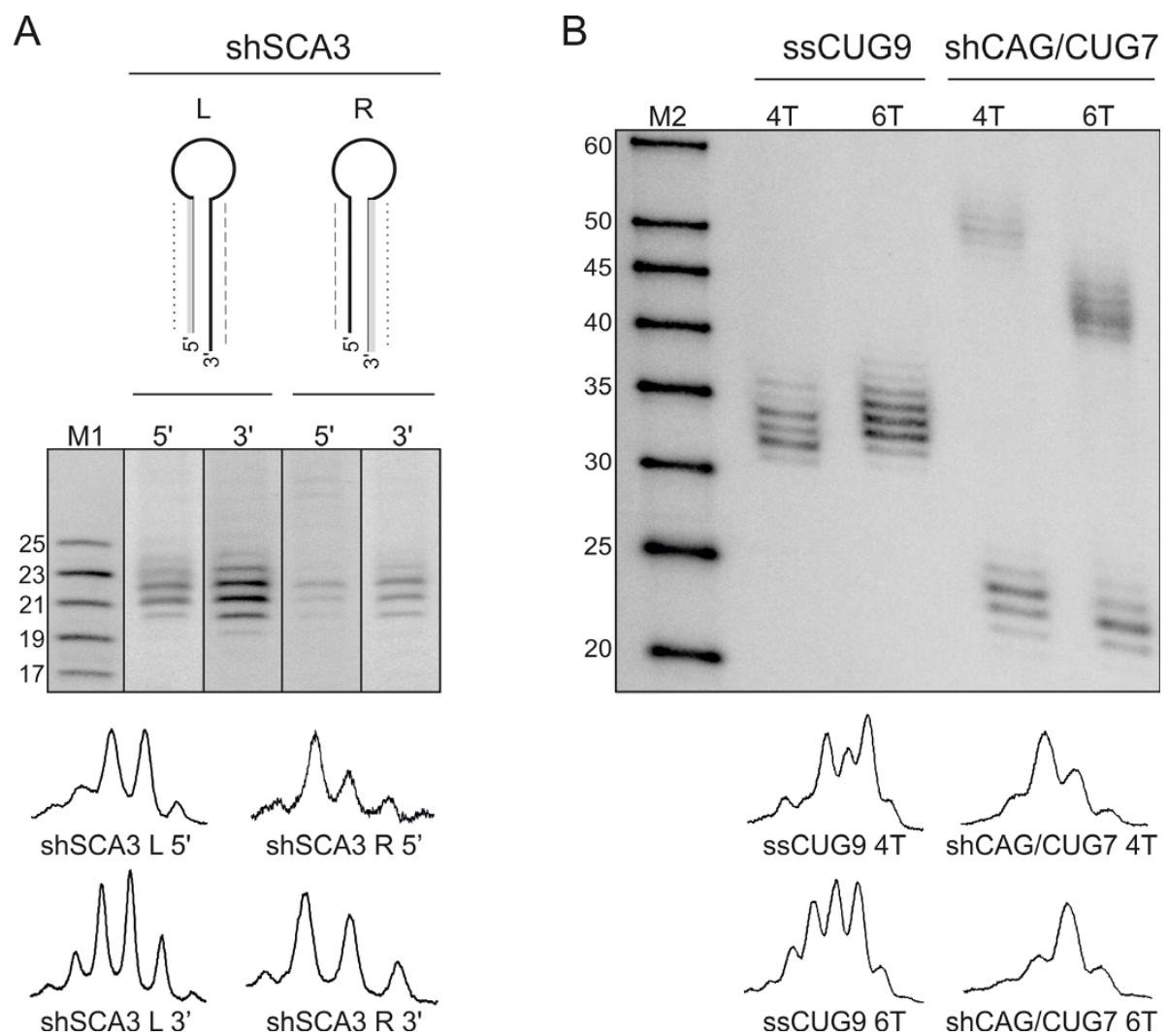

Figure 3 Application of the high-resolution northern blotting in monitoring RNA reagents expressed in cells. A) Processing of antisensesense and sense-antisense shRNAs (L-shSCA3 and R-shSCA3, respectively). The $5^{\prime}$ and $3^{\prime}$ strands of each shRNA were analyzed by detection with probes complementary to either siRNA strand, as indicated in the figure. One probe detected L-5' and R-3' strands (dotted line) while the other probe detected L-3' and R-5' strands (dashed line). B) ssRNA CUG9 and shRNA CAG/CUG7 transcribed from vectors, having either 4T or 6T at their termination sites. M denotes size markers; M1 denotes end-labeled 17, 19, 21, 23, and 25-nt synthetic RNA oligonucleotides and M2 denotes RNA Low Molecular Weight Marker (USB). Quantitative representations of siRNA length variants are shown in the bottom panel, using peaks obtained from phosphorimaging analyses.

complete and more reliable information about the exact lengths and end-sequences of miRNA and cell-expressed siRNA variants. Such information is very important as miRNA and siRNA variants having different 5' ends may differ in the potency to activate RISC [27,49], as well as in downstream silencing effects. RISC programmed by different miRNA 5'-end variants may regulate different targets [24,28-30], and programmed by siRNA variants may cleave mRNAs at shifted sites compromising the allele-specific SNP-targeting applications.

\section{Methods}

\section{Animals}

The animals were kept under standard conditions with a 12-h light/dark cycle and water and food ad libitum. The animals were sacrificed by placing them in a $70 \%$ $\mathrm{CO}_{2}$ atmosphere. The original strains $\mathrm{C} 57 \mathrm{BL} / 6 \mathrm{~J}$ and $\mathrm{C} 3 \mathrm{H} / \mathrm{HeJ}$ were obtained from The Jackson Laboratory (Bar Harbor, Maine; USA) and were bred to B6C3F1.
The study was carried out in strict accordance with Polish Law on Animal Experimentation which complies with EU standards. All procedures and animal handling were carried out to minimize animal stress and were approved and monitored by The Local Ethical Commission for Animal Experiments in Poznan (Decision Number: 49/2010).

\section{Cell culture}

HEK 293T cells were obtained from the American Type Culture Collection (ATCC) and grown in Dulbecco's Modified Eagle's Medium (DMEM, Lonza) with 10\% fetal bovine serum (FBS, Sigma-Aldrich) and Antibiotic Antimycotic Solution (Sigma-Aldrich) at $37^{\circ} \mathrm{C}$ in a humidified atmosphere of $5 \% \mathrm{CO}_{2}$.

\section{DNA transfection}

HEK 293T cells were grown to $90 \%$ confluence in T-25 flasks and transfected with $3 \mu \mathrm{g}$ of either plasmid 
constructs (System Biosciences) encoding appropriate miRNA precursors or plasmid vectors (pSilencer 3.1-H.1 hygro, Ambion) containing specific expression cassettes (shRNA) (Additional file 1: Supplemental Table S2), using Lipofectamine 2000 (Invitrogen). The cells were harvested 24 hours after transfection, and isolated RNAs were analyzed by northern blotting.

\section{RNA isolation and northern blotting of miRNAs and pre- miRNAs}

Total RNA was extracted from the cells and selected mouse brain and muscle tissues using TRI Reagent (MRC, Inc., BioShop) according to the manufacturer's instructions. RNAs $(20-30 \mu \mathrm{g})$ were resolved on denaturing polyacrylamide gels (12\% PAA, 19:1 acrylamide/bis, $7 \mathrm{M}$ urea) in $0.5 \times$ TBE. Two separate electrophoresis runs were performed, as described previously $[26,50]$. Briefly, a vertical electrophoresis gel system (II xi Cell, BioRad) for resolution of miRNAs, and a model S2 sequencing gel electrophoresis apparatus (Gibco, Life Technologies) for pre-miRNA separations were used. Xylene cyanol dye (XC) migrated $10 \mathrm{~cm}$ and $30 \mathrm{~cm}$, for high resolution of miRNA and pre-miRNA fractions, respectively. Marker lanes contained a mixture of simultaneously radiolabeled synthetic RNA oligonucleotides (ORNs: 17-, 19-, 21-, 23-, 25-nt or ORNs: 60-, 61-, 63-, 64-nt) or RNA Low Molecular Weight Marker (USB). RNAs were transferred to GeneScreen Plus hybridization membrane (PerkinElmer) using semi-dry electroblotting (Sigma-Aldrich), immobilized by subsequent UV irradiation $\left(120 \mathrm{~mJ} / \mathrm{cm}^{2}\right)(\mathrm{UVP})$ and baked in an oven at $80^{\circ} \mathrm{C}$ for $30 \mathrm{~min}$. The membranes were probed with specific oligodeoxynucleotides (ODNs) complementary to the annotated mouse miRNAs miR-9, $-9^{*},-93,-29 a,-29 b$, $-124,-132,-137,-191,-496,-1$ and -206 (miRBase) and to 21-nt siRNAs generated from shRNAs (Additional file 1: Supplemental Table S3). The ODNs were labeled with $\left[\gamma^{32} \mathrm{P}\right]$ ATP $(5000 \mathrm{Ci} / \mathrm{mmol}$, Hartmann Analytics) using OptiKinase (USB) according to the manufacturer's instructions. Pre-hybridizations and hybridizations were carried out under the same conditions at $37^{\circ} \mathrm{C}$ overnight in buffer containing $5 \times$ SSC, $1 \%$ SDS and $1 \times$ Denhardt's solution. After hybridization, the membranes were washed three times in a low-stringency buffer solution $(2 \times$ SSC and $0.1 \%$ SDS) for 20 minutes. Radioactive signals were quantified by phosphorimaging (Multi Gauge v3.0, Fujifilm).

\section{Additional material}

Additional file 1: Supplemental tables S1, S2 and S3.

\section{Acknowledgements}

We would like to thank Maciej Figiel and Pawel Switonski for providing mouse tissues for miRNA expression analyses.
This work was supported by the Polish Ministry of Science and Higher Education (grant numbers N N301 523038 and N N301 284837) and by the European Regional Development Fund within the Innovative Economy Programme (POIG.01.03.01-30-098/08).

\section{Authors' contributions}

EK, JS-R, LJS, MO, PG-M performed experiments and analyzed data. EK drafted the manuscript. WJK conceived the study, supervised the research and contributed in the preparation of the paper. All authors read and approved the final manuscript.

Received: 7 January 2011 Accepted: 11 April 2011

Published: 11 April 2011

\section{References}

1. Croce $C M$ : Causes and consequences of microRNA dysregulation in cancer. Nat Rev Genet 2009, 10:704-714.

2. Friedman JM, Jones PA: MicroRNAs: critical mediators of differentiation, development and disease. Swiss Med Wkly 2009, 139:466-472.

3. Gomase VS, Parundekar AN: microRNA: human disease and development. Int J Bioinform Res Appl 2009, 5:479-500.

4. Hebert SS, De Strooper B: Alterations of the microRNA network cause neurodegenerative disease. Trends Neurosci 2009, 32:199-206.

5. Williams AH, Liu N, van Rooij E, Olson EN: MicroRNA control of muscle development and disease. Curr Opin Cell Biol 2009, 21:461-469.

6. Xiao C, Rajewsky K: MicroRNA control in the immune system: basic principles. Cell 2009, 136:26-36.

7. Harrison C: Cardiovascular disorders: MicroRNA modulation of cholesterol. Nat Rev Drug Discov 2010, 9:515.

8. Lau P, de Strooper B: Dysregulated microRNAs in neurodegenerative disorders. Semin Cell Dev Biol 2010, 21:768-773.

9. Miller BH, Wahlestedt C: MicroRNA dysregulation in psychiatric disease. Brain Res 2010, 1338:89-99.

10. Winter J, Jung S, Keller S, Gregory Rl, Diederichs S: Many roads to maturity: microRNA biogenesis pathways and their regulation. Nat Cell Biol 2009, 11:228-234.

11. Kim VN, Han J, Siomi MC: Biogenesis of small RNAs in animals. Nat Rev Mol Cell Biol 2009, 10:126-139.

12. Krol J, Loedige I, Filipowicz W: The widespread regulation of microRNA biogenesis, function and decay. Nat Rev Genet 2010, 11:597-610.

13. Siomi H, Siomi MC: Posttranscriptional regulation of microRNA biogenesis in animals. Mol Cell 2010, 38:323-332.

14. Denli AM, Tops BB, Plasterk RH, Ketting RF, Hannon GJ: Processing of primary microRNAs by the Microprocessor complex. Nature 2004, 432:231-235

15. Gregory RI, Yan KP, Amuthan G, Chendrimada T, Doratotaj B, Cooch N, Shiekhattar R: The Microprocessor complex mediates the genesis of microRNAs. Nature 2004, 432:235-240.

16. Lund E, Guttinger S, Calado A, Dahlberg JE, Kutay U: Nuclear export of microRNA precursors. Science 2004, 303:95-98

17. Zeng $Y$, Cullen BR: Structural requirements for pre-microRNA binding and nuclear export by Exportin 5. Nucleic Acids Res 2004, 32:4776-4785.

18. Haase AD, Jaskiewicz L, Zhang H, Laine S, Sack R, Gatignol A, Filipowicz W: TRBP, a regulator of cellular PKR and HIV-1 virus expression, interacts with Dicer and functions in RNA silencing. EMBO Rep 2005, 6:961-967.

19. Zhang H, Kolb FA, Jaskiewicz L, Westhof E, Filipowicz W: Single processing center models for human Dicer and bacterial RNase III. Cell 2004, 118:57-68.

20. Khvorova A, Reynolds A, Jayasena SD: Functional siRNAs and miRNAs exhibit strand bias. Cell 2003, 115:209-216.

21. Schwarz DS, Hutvagner G, Du T, Xu Z, Aronin N, Zamore PD: Asymmetry in the assembly of the RNAi enzyme complex. Cell 2003, 115:199-208.

22. Landgraf $P$, Rusu M, Sheridan R, Sewer A, lovino N, Aravin A, Pfeffer S, Rice A, Kamphorst AO, Landthaler $\mathrm{M}$, et al: A mammalian microRNA expression atlas based on small RNA library sequencing. Cell 2007, 129:1401-1414.

23. Morin RD, O'Connor MD, Griffith M, Kuchenbauer F, Delaney A, Prabhu AL, Zhao Y, McDonald H, Zeng T, Hirst M, et al: Application of massively parallel sequencing to microRNA profiling and discovery in human embryonic stem cells. Genome Res 2008, 18:610-621. 
24. Chiang HR, Schoenfeld LW, Ruby JG, Auyeung VC, Spies N, Baek D, Johnston WK, Russ C, Luo S, Babiarz JE, et al: Mammalian microRNAs: experimental evaluation of novel and previously annotated genes. Genes Dev 2010, 24:992-1009.

25. Marti E, Pantano L, Banez-Coronel M, Llorens F, Minones-Moyano E, Porta S, Sumoy L, Ferrer I, Estivill X: A myriad of miRNA variants in control and Huntington's disease brain regions detected by massively parallel sequencing. Nucleic Acids Res 2010, 38:7219-7235.

26. Starega-Roslan J, Krol J, Koscianska E, Kozlowski P, Szlachcic WJ, Sobczak K Krzyzosiak WJ: Structural basis of microRNA length variety. Nucleic Acids Res 2011, 39:257-268.

27. Frank F, Sonenberg N, Nagar B: Structural basis for 5'-nucleotide basespecific recognition of guide RNA by human AGO2. Nature 2010, 465:818-822.

28. Kawahara $Y$, Megraw M, Kreider $E$, lizasa H, Valente L, Hatzigeorgiou AG, Nishikura K: Frequency and fate of microRNA editing in human brain. Nucleic Acids Res 2008, 36:5270-5280.

29. Seitz H, Ghildiyal M, Zamore PD: Argonaute loading improves the $5^{\prime}$ precision of both MicroRNAs and their miRNA* strands in flies. Curr Biol 2008, 18:147-151.

30. Wu H, Neilson JR, Kumar P, Manocha M, Shankar P, Sharp PA, Manjunath N: miRNA profiling of naive, effector and memory CD8 T cells. PLOS One 2007, 2:e1020.

31. Olejniczak M, Galka P, Krzyzosiak WJ: Sequence-non-specific effects of RNA interference triggers and microRNA regulators. Nucleic Acids Res 2010, 38:1-16

32. Fedorov $Y$, Anderson EM, Birmingham A, Reynolds A, Karpilow J, Robinson K, Leake D, Marshall WS, Khvorova A: Off-target effects by siRNA can induce toxic phenotype. RNA 2006, 12:1188-1196.

33. Jackson AL, Bartz SR, Schelter J, Kobayashi SV, Burchard J, Mao M, Li B, Cavet G, Linsley PS: Expression profiling reveals off-target gene regulation by RNAi. Nat Biotechnol 2003, 21:635-637.

34. Kim SW, Li Z, Moore PS, Monaghan AP, Chang Y, Nichols M, John B: A sensitive non-radioactive northern blot method to detect small RNAs. Nucleic Acids Res 2010, 38:e98.

35. Pall GS, Codony-Servat C, Byrne J, Ritchie L, Hamilton A: Carbodiimidemediated cross-linking of RNA to nylon membranes improves the detection of siRNA, miRNA and piRNA by northern blot. Nucleic Acids Res 2007, 35:e60.

36. Pall GS, Hamilton AJ: Improved northern blot method for enhanced detection of small RNA. Nat Protoc 2008, 3:1077-1084.

37. Valoczi A, Hornyik C, Varga N, Burgyan J, Kauppinen S, Havelda Z: Sensitive and specific detection of microRNAs by northern blot analysis using LNA-modified oligonucleotide probes. Nucleic Acids Res 2004, 32:e175.

38. Varallyay E, Burgyan J, Havelda Z: Detection of microRNAs by Northern blot analyses using LNA probes. Methods 2007, 43:140-145.

39. Varallyay E, Burgyan J, Havelda Z: MicroRNA detection by northern blotting using locked nucleic acid probes. Nat Protoc 2008, 3:190-196.

40. Diederichs $S$, Haber DA: Dual role for argonautes in microRNA processing and posttranscriptional regulation of microRNA expression. Cell 2007, 131:1097-1108

41. Calabrese JM, Seila AC, Yeo GW, Sharp PA: RNA sequence analysis defines Dicer's role in mouse embryonic stem cells. Proc Natl Acad Sci USA 2007, 104:18097-18102.

42. Wu H, Ye C, Ramirez D, Manjunath $\mathrm{N}$ : Alternative processing of primary microRNA transcripts by Drosha generates $5^{\prime}$ end variation of mature microRNA. PLoS One 2009, 4:e7566.

43. Ruby JG, Jan C, Player C, Axtell MJ, Lee W, Nusbaum C, Ge H, Bartel DP. Large-scale sequencing reveals 21U-RNAs and additional microRNAs and endogenous siRNAs in C. elegans. Cell 2006, 127:1193-1207.

44. Ge Q, Ilves H, Dallas A, Kumar P, Shorenstein J, Kazakov SA, Johnston BH: Minimal-length short hairpin RNAs: the relationship of structure and RNAi activity. RNA 2010, 16:106-117.

45. Scherer $L$, Rossi JJ: Approaches for the sequence-specific knockdown of mRNA. Nat Biotechnol 2003, 21:1457-1465.

46. Paul CP, Good PD, Winer I, Engelke DR: Effective expression of small interfering RNA in human cells. Nat Biotechnol 2002, 20:505-508.

47. Li L, Lin X, Khvorova A, Fesik SW, Shen Y: Defining the optimal parameters for hairpin-based knockdown constructs. RNA 2007, 13:1765-1774.
48. Moore CB, Guthrie EH, Huang MT, Taxman DJ: Short hairpin RNA (shRNA): design, delivery, and assessment of gene knockdown. Methods Mol Biol 2010, 629:141-158

49. Okamura K, Liu N, Lai EC: Distinct mechanisms for microRNA strand selection by Drosophila Argonautes. Mol Cell 2009, 36:431-444.

50. Koscianska E, Starega-Roslan J, Czubala K, Krzyzosiak WJ: High-resolution northern blot for a reliable analysis of microRNAs and their precursors. ScientificWorldJournal 2011, 11:102-117.

doi:10.1186/1471-2199-12-14

Cite this article as: Koscianska et al:: Northern blotting analysis of microRNAs, their precursors and RNA interference triggers. BMC

Molecular Biology 2011 12:14.

\section{Submit your next manuscript to BioMed Central and take full advantage of:}

- Convenient online submission

- Thorough peer review

- No space constraints or color figure charges

- Immediate publication on acceptance

- Inclusion in PubMed, CAS, Scopus and Google Scholar

- Research which is freely available for redistribution

Submit your manuscript at www.biomedcentral.com/submit
C Biomed Central 